\title{
Techno-Economic Assessment of Hybrid Energy Off-Grid System - A Case Study for Masirah Island in Oman
}

\author{
Hilal Mohamed Al Ghaithi ${ }^{1}$, George P. Fotis ${ }^{2}$, Vasiliki Vita ${ }^{1,2}$ \\ ${ }^{1}$ Department of Electrical and Electronic Engineering, City, University of London, London EC1V 0HB, United \\ Kingdom \\ ${ }^{2}$ Department of Electrical and Electronic Engineering Educators, A.S.PE.T.E. - School of Pedagogical and \\ Technological Education, N. Heraklion, 14121 Athens, Greece \\ Email: vasvita@aspete.gr
}

\begin{abstract}
Hybrid energy systems can provide various benefits to an island diesel power system. This paper analyses the technical and economic viability of hybrid energy system in the Masirah Island power system in Oman. The methodology involves the use of Hybrid Optimization Model for Electric Renewable (HOMER) for the optimization of the proposed hybrid system. The simulation software package DIgSILENT is used to model and simulate the integration of the proposed hybrid system to the existing network. Different scenarios are considered in both the hybrid system optimization and the assessment of the impact of the hybrid energy system integration implemented different connection scenarios. The obtained results show that the hybrid energy system composed of diesel, photovoltaic and wind generator units is the most economically feasible option since it provides the lowest system net present cost, operating cost and cost of energy, while it also improves the voltage profile at the point of connection.
\end{abstract}

Keywords: DIgSILENT, hybrid energy systems, HOMER, optimization, simulation.

\section{Introduction}

Renewable energy technologies are widely used in powering off-grid systems including island power systems. Many islands around the world depend on only one source of generation, mainly diesel-based electricity for supplying local loads. However, this is not the most economical option due to the high cost of imported diesel fuel. The usage of renewable energy generation in island mini-grid power systems has been considered as a cost effective option for replacing the high cost of diesel generation [1].

Furthermore, renewable energy has not been considered as a fully reliable source compared to conventional sources of electricity due to the intermittency issues related to its generation. To overcome the issue of variability of renewable energy many solutions have been implemented including hybrid energy systems, which are considered a widely implemented alternative solution [2]. Hybrid energy systems can be composed of two or more sources of generation from both conventional and renewable technologies [3]. Different criteria of sizing the different system components of hybrid renewable energy power plant at the most preferable environmental and economical way have been presented in $[4,5]$, while some of the optimization approaches which are used to compare the energy production cost and performance of different hybrid system configurations using simulation techniques have been presented in $[6]$.

In order to establish an optimal combination of hybrid energy system components, different techniques including computer analytical tools have been developed and used. This is to ensure that hybrid energy systems have the technical capability to provide reliable and secure supply in order to meet demand at the least possible cost. In addition, integration of hybrid energy systems to the power networks may cause reliability and stability issues. Therefore, simulations of the analysis are implemented to assess the possible impact that hybrid energy system may have on system networks [7, $8]$. 


\section{The Masirah Island Case Study}

The main objective of this work is to investigate the technical and economic feasibility of a hybrid energy system integrated to the existing diesel off-grid/isolated power system in the Masirah Island in the Sultanate of Oman. The Masirah Island is Oman's largest island with an area of about $649 \mathrm{~km}^{2}$ and a population estimated at 12,825 in 2013 . The distance between the island and the main land is about $15 \mathrm{~km}$. The island's off-grid/isolated power system depends fully on a diesel generating plant, having a total installed capacity of $20.3 \mathrm{MW}$ in 2014 with net available capacity of $16.7 \mathrm{MW}$. The local power company is responsible for the operating of the diesel power station, distribution and low voltage network as well as of a small water desalination plant [9].

The network peak demand in 2014 was around 13.4 MW with an annual forecasted growth of $7 \%$. Masirah Island has a significant potential for solar and wind energy resources [3]. The high forecasted demand growth for electricity in Masirah Island will impose significant constraints on continuing to use expensive, high emission producing diesel fuel. Due to the fact that the mainland side opposite to the island is also supplied by diesel fuel the option of importing electricity through a submarine cable is omitted. On the other hand, construction of a gas power plant is not an economically viable option due to the high expected cost of transporting the gas to the island.

Therefore, utilizing the island's local solar and wind resources should be considered as an alternative option for reducing the cost of electricity generation, reducing emissions and enhancing security of supply. Renewable energy sources such as wind and solar energy are widely used in powering island systems. However, due to the intermit nature of these sources, hybrid renewable energy systems are used to overcome the issue of solar and wind energy variability. Hybrid energy systems provide continuous and reliable electricity supply in cases when either solar or wind is not available and are confirmed to reduce the cost of energy produced. The use of a hybrid energy system minimizes emissions through the reduction of diesel generation unit operation. On the other hand, implementing a hybrid renewable energy system requires a detailed assessment of the optimal size of each technology. In addition, simulation of the hybrid system is also required to confirm power flows and compliance with the network voltage regulation [10].

In this paper the technical and economic feasibility of a hybrid energy system integrated with an offgrid power system is investigated. This is achieved by collecting all required data and implementing proper data analysis to obtain input for the optimization and simulation software. HOMER software [11] was used to run an optimization analysis of the optimal size of the hybrid energy system. Simulation of the proposed hybrid energy system to assess the integration impact was achieved by using the capabilities of the DIgSILENT Power Factory software [12].

\section{Economic and Technical Feasibility of Hybrid Energy Systems}

The economic study of a hybrid renewable energy system is based on a financial evaluation of different configurations of hybrid systems. The economic feasibility of a hybrid renewable system is analyzed based on following parameters [13]:

Payback period: It is the time in which initial investment is expected to recover from the cash inflow generated by the investment in the hybrid renewable energy system.

Internal rate of return: The annualized compounded rate of return that makes the net present value of the hybrid renewable energy system equal to zero.

Net present cost (NPC): The total net present cost includes initial capital cost of the system, cost of replacement components and other cost that include fuel and maintenance charges.

Cost of energy (COE): The energy cost of the hybrid renewable system is calculated by using (1):

$$
\text { Per unit energy cost }=\frac{\text { ALCC }}{365 \cdot \text { Average Daily Load Demand }}
$$

where:

ALCC is the annualized life cycle cost. 


\section{Methodology}

\subsection{Methodology Framework}

HOMER software is used for optimizing the hybrid energy system and DIgSILENT PowerFactory is used for analysing the proposed hybrid system. Fig. 1 presents the methodology framework that is followed in this work.

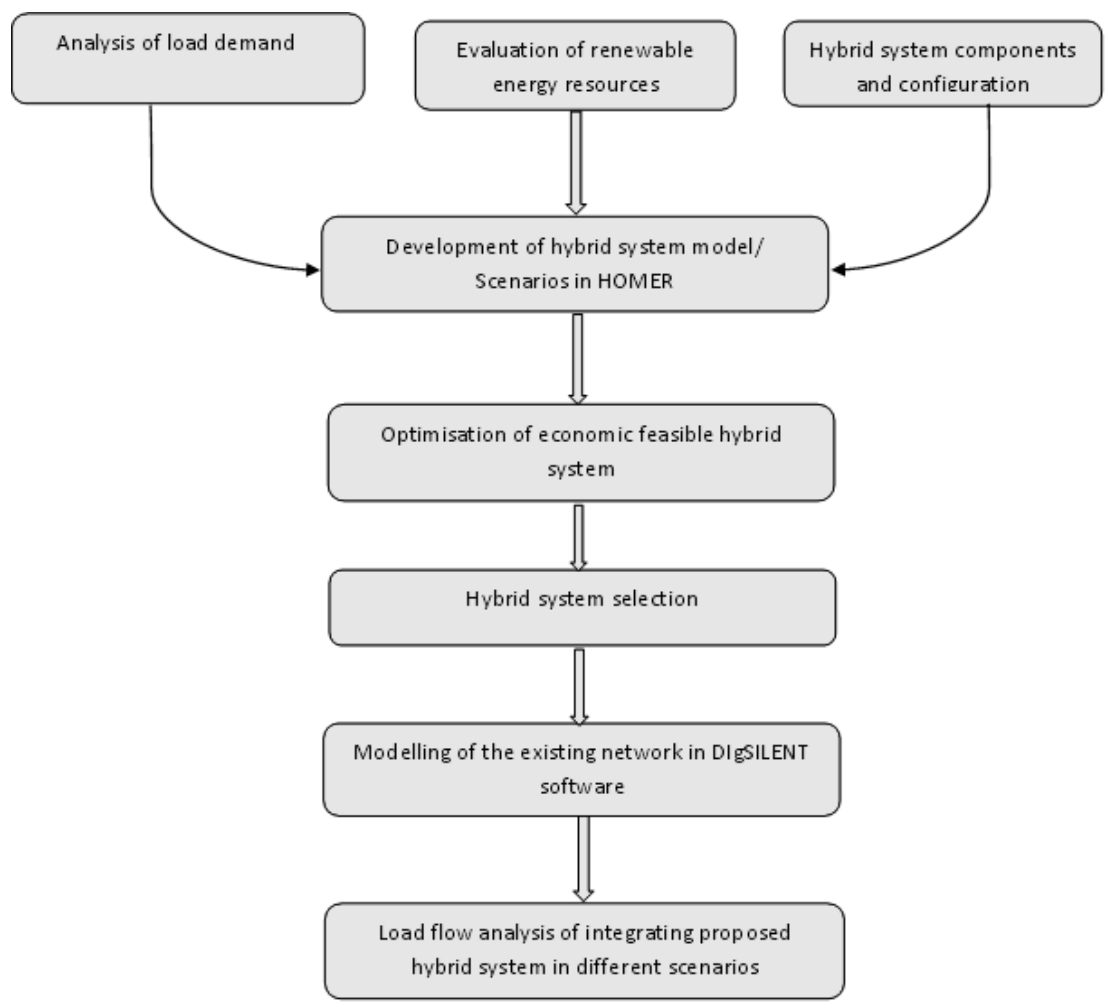

Figure 1. Methodology framework.

\subsection{Data Collection}

The load profile data of the selected site, the Masirah Island, was obtained from the local power company. Around 50-60\% of the total demand in such system is mainly driven by the residential customers [10]. The remaining load is consumed by government offices and small businesses. The 2014 load profile of the island is shown in Fig. 2.

The solar energy resources in the Sultanate of Oman are considered among the highest globally [3]. This provides significant potential for developing solar energy projects all around the country, especially in the desert areas [15]. Fig. 3a presents the monthly average solar radiation in the Masirah Island [16]. The solar energy can provide a significant contribution for meeting the system high demands in summer and therefore reduce the operation and cost of running diesel generation. The Masirah Island has also considerable potential for wind energy. The island is one of the windiest places in the country. The monthly average wind speed at $50 \mathrm{~m}$ height is presented in Fig. 3b [16]. Similar to solar resources, the highest wind speeds in the island are observed during the summer months. 


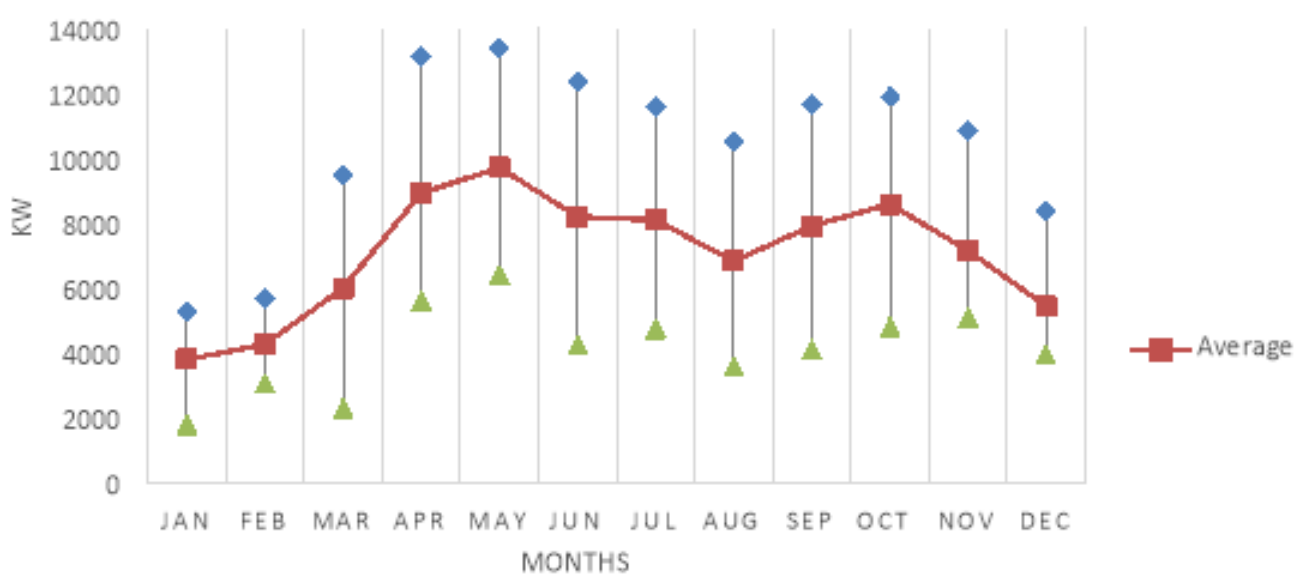

Figure 2. Masirah Island 2014 load profile.

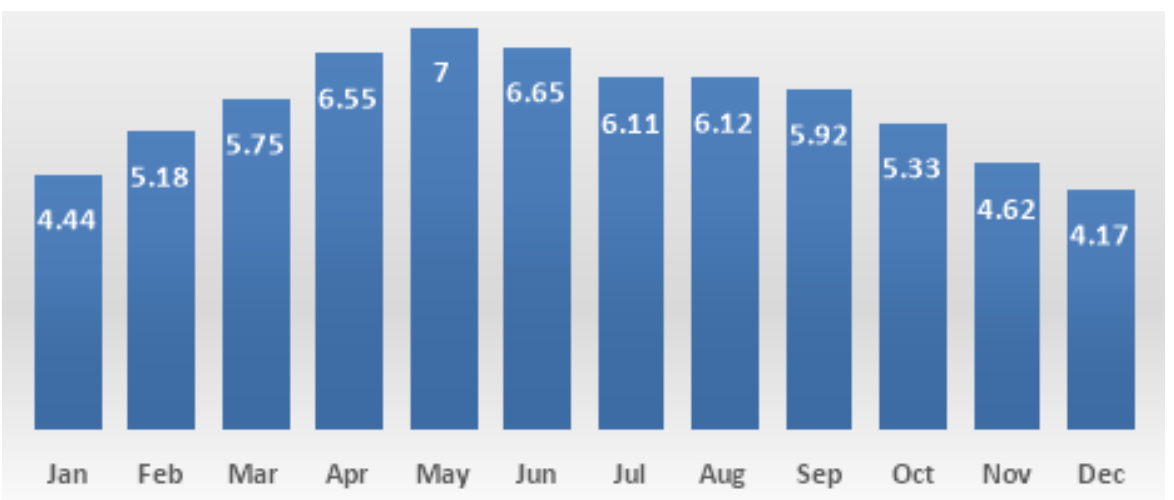

(a)

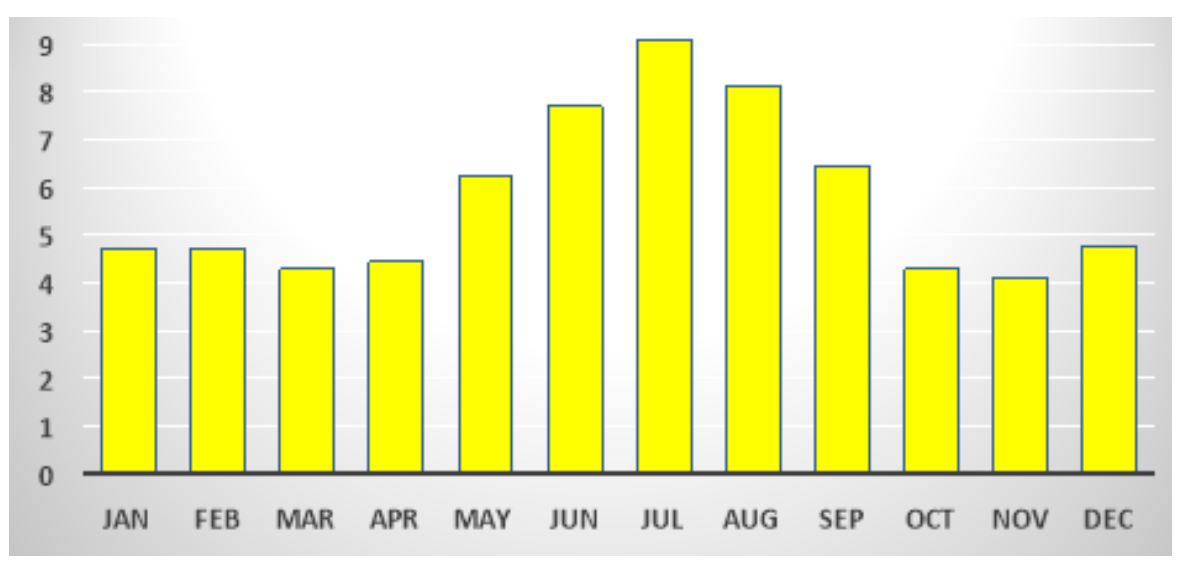

(b)

Figure 3. Data of renewable energy resources. (a) Average solar radiation data for Masirah Island (in $\mathrm{kWh} / \mathrm{km}^{2} /$ day) [16] and (b) Average wind speed (in $\mathrm{m} / \mathrm{sec}$ ) [16]. 


\subsection{Hybrid System Modeling}

HOMER software provides users with the capability to evaluate different system configurations in a simplified method. Different systems can be evaluated using HOMER including grid and off-grid rural power systems and distributed generation. The optimization analysis in HOMER also provides users with the capability of assessing the technical and economic feasibility of different types of technologies taking into account parameters such as costs, system load and renewable energy resources. The sensitivity analysis evaluates the impact on the system costs and optimal size selection as an effect of input variable uncertainty. The results of the optimal hybrid system are based on the total costs of the project. This means regardless of the input sizes of each component; the system configuration with the lowest total system cost is defined as the optimal hybrid system [17].

The optimization analysis, which is based on energy balance, requires several inputs including resource data, load data, technology components and costs. By comparing the energy produced by different components and the system load profile on an hourly basis throughout the year, HOMER determines whether the modeled system would be able to supply the given system demand. Once the configuration of the hybrid system is identified based on the conditions specified by the user, the HOMER calculates the NPC, the operating cost and the Levelised Cost of Energy (LCOE) [17].

\subsection{Hybrid System Components}

To utilize the local renewable energy resources, hybrid energy systems are designed to operate with diesel generator either alternatively or in parallel. There are different types of hybrid systems that are classified based on the voltage and bus type in which the different generation systems are connected. These classifications are AC or DC or DC/AC coupled systems [3].

In order to utilize the maximum output of the generating units and to supply the AC system peak load, inverters and rectifiers are appropriately sized. Considering that the existing power system in the island is operating as an AC bus system, the AC coupled hybrid system is selected to be used in this work. The diesel generation is the main source of generation in the proposed hybrid energy system. The renewable energy technologies are planned to reduce the overall system costs by reducing the operation of diesel generators and enhance system reliability. Table 1 presents details of the existing diesel units as obtained from the local power company.

Table 1. Details of the existing diesel units in Masirah Diesel Power Station.

\begin{tabular}{ccc}
\hline Engine No. & Manufacturer & Installed Capacity $(\mathbf{k W})$ \\
\hline 1 & MBS & 265 \\
2 & MBS & 265 \\
3 & MBS & 265 \\
4 & MBS & 265 \\
5 & MBS & 265 \\
6 & KHD & 3000 \\
7 & KHD & 3000 \\
8 & Caterpillar & 1000 \\
9 & Caterpillar & 1000 \\
10 & CUMMINS & 1000 \\
11 & KHD & 3000 \\
12 & KHD & 3000 \\
13 & MAN & 4000 \\
\hline
\end{tabular}

All diesel generators were modeled in HOMER using their installed capacity as given in Table 1. Furthermore input variables such as capital cost, operation and maintenance cost and diesel fuel price were used in the modeling. Table 2 illustrates the different costs used for diesel generators and provides all input variables used in the modeling and optimization of the hybrid energy system in HOMER software. The optimization analysis was based on the economic minimization of system control and load 
based on a dispatch strategy. In other words the software identifies the optimal hybrid system that has the minimum cost.

Table 2. Input variables to HOMER

\begin{tabular}{ll}
\hline Solar PV & \\
\hline Capital cost & 3,000 USD per kW \\
O\&M & 30 USD per year per kW \\
Lifetime & $25 \mathrm{yr}$ \\
Sizes considered & $0,1000,1500,2000,2500,3000$ \\
\hline Diesel generators & \\
\hline Capital cost & $750 \mathrm{USD}$ per kW \\
Replacement cost & $750 \mathrm{USD}$ per kW \\
O\&M & $0.1 \mathrm{USD} / \mathrm{hr}$ \\
Lifetime & $25,000 \mathrm{hrs}$ \\
Fuel price & $0.64 \mathrm{USD} / \mathrm{L}$ \\
\hline Wind Turbine & \\
\hline Type & Vergnet GEV MP-R \\
Capacity & $275 \mathrm{~kW}$ \\
Capital cost & $400,000 \mathrm{USD}$ \\
Replacement cost & $350,000 \mathrm{USD}$ \\
O\&M & $600 \mathrm{USD}$ \\
Sizes considered & $0,2,4,6,8,10$ \\
\hline Converter & \\
\hline Capital cost & $500 \mathrm{USD}$ per kW \\
Replacement cost & $350 \mathrm{USD}$ per kW \\
Operation and maintenance & $5 \mathrm{USD} / \mathrm{yr} / \mathrm{kW}$ \\
Sizes to consider & $0,500,1000,1500,2000,2500,3000 \mathrm{~kW}$ \\
Lifetime & $15 \mathrm{yr}$ \\
Inverter efficiency & $95 \%$ \\
\hline Economics & $25 \mathrm{yr}$ \\
\hline Annual discount rate & $1,000,000 \mathrm{USD}$ \\
Project lifetime & \\
\hline System fixed capital cost & \\
\hline
\end{tabular}

\subsection{Optimization Scenarios in HOMER}

Three different scenarios were considered for the optimization of the hybrid energy system:

Base-case scenario - Diesel system: An optimization analysis is performed in the existing diesel system to obtain the total system costs including capital cost, fuel cost, operating cost and cost of energy of the diesel generation.

Diesel - Solar PV hybrid system: An optimization analysis is performed in a hybrid energy system consisting of a diesel and a solar PV.

Diesel - Solar PV - Wind generator hybrid system: An optimization analysis is performed in a hybrid energy system consisting of a diesel, a solar PV and a wind generator. 


\subsection{Simulations in DIgSILENT}

In order to access the impact of integrating the proposed hybrid system on the existing network, power systems software DIgSILENT PowerFactory version 15.2 was used [10]. Distributed generation (DG) once connected to the distribution network can have significant impact on the power flow and voltage profile on both system and customers side. The nominal voltage and frequency limits used in the simulations are the ones used by the local power company [9], i.e., frequency of $50 \mathrm{~Hz} \pm 0.05$ and nominal voltages of $33 \mathrm{kV}$ and $11 \mathrm{kV} \pm 6 \%$.

The single line diagram of the modified network is presented in Fig. 4. The current system in the island is supplied by 13 diesel generating units. The diesel power plant is connected to the main $11 \mathrm{kV}$ busbar of the system. Most parts of the network operate at $11 \mathrm{kV}$ apart from two $33 \mathrm{kV}$ feeders used to transport electricity for long distances. Due to the local weather conditions on the island, the local power company operates only 33 and $11 \mathrm{kV}$ cables. There are 4 power transformers of $33 \mathrm{kV} / 11 \mathrm{kV}$ of 10 MVA rating. Details of the network load and equipment are provided in Table 3 and Table 4.

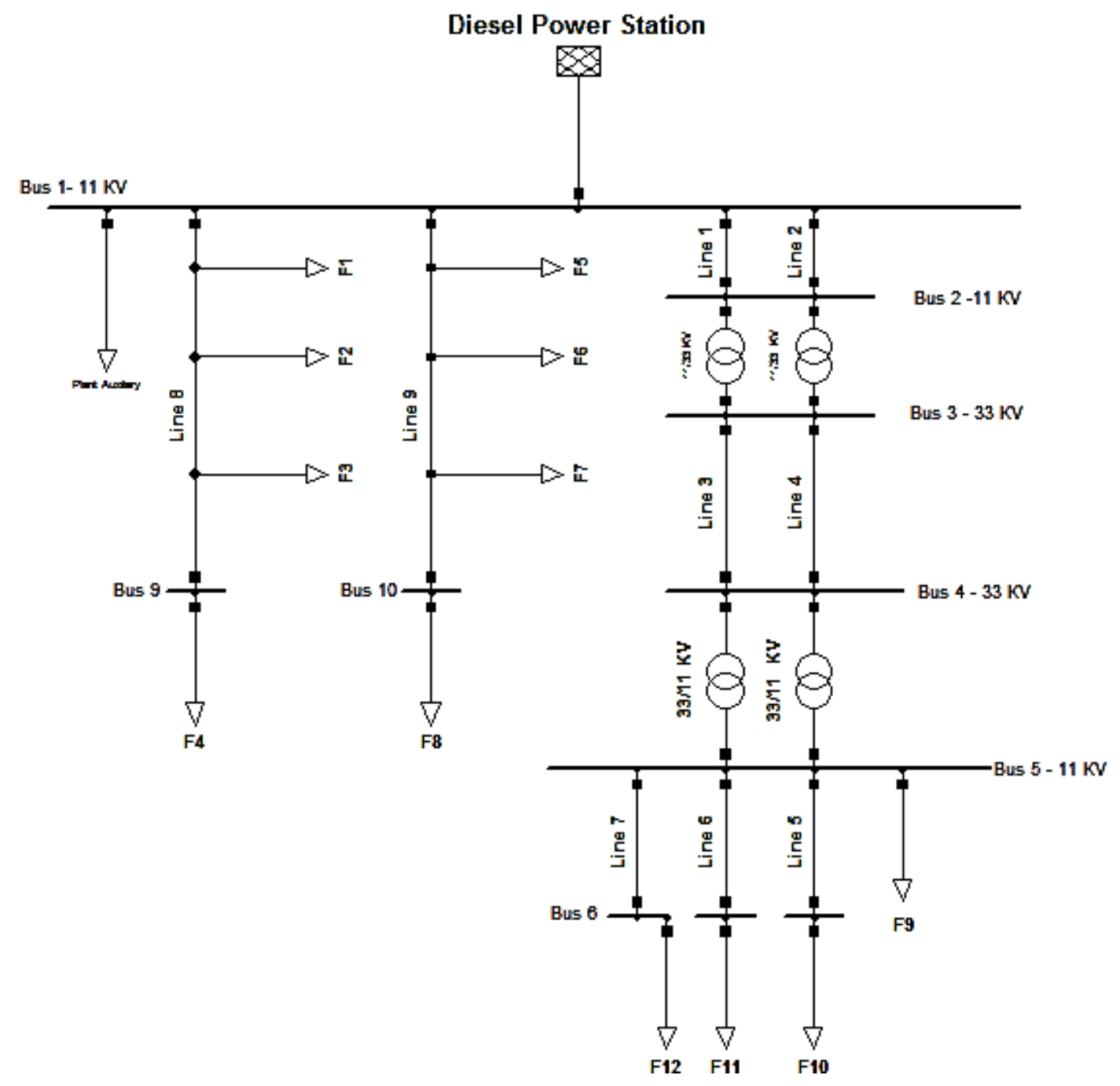

Figure 4. Single line diagram of the network. 
Table 3. Details of the network loads.

\begin{tabular}{cccc}
\hline Load Name & Terminal busbar & Active power (MW) & Reactive power (MVar) \\
\hline F1 & Node 1 & 0.65 & 0.395 \\
F2 & Node 2 & 0.65 & 0.39 \\
F3 & Node 3 & 0.65 & 0.39 \\
F4 & Bus 9 & 0.65 & 0.4 \\
F5 & Node 4 & 0.76 & 0.43 \\
F6 & Node 5 & 0.76 & 0.43 \\
F7 & Node 6 & 0.76 & 0.43 \\
F8 & Bus 10 & 0.76 & 0.45 \\
F9 & Bus 5 & 0.05 & 0.03 \\
F10 & Bus 8 & 0.65 & 0.38 \\
F11 & Bus 7 & 1.3 & 0.8 \\
F12 & Bus 6 & 3.4 & 2.0 \\
\hline
\end{tabular}

Table 4. Details of the network cables.

\begin{tabular}{cccc}
\hline Line Name & $\begin{array}{c}\text { Terminal i } \\
\text { (From) }\end{array}$ & $\begin{array}{c}\text { Terminal j } \\
\text { (To) }\end{array}$ & Length (km) \\
\hline Line 1 & Bus 1 & Bus 2 & 0.46 \\
Line 2 & Bus 1 & Bus 2 & 0.46 \\
Line 3 & Bus 3 & Bus 4 & 5.0 \\
Line 4 & Bus 3 & Bus 4 & 5.0 \\
Line 5 & Bus 5 & Bus 8 & 10.13 \\
Line 6 & Bus 5 & Bus 7 & 4.0 \\
Line 7 & Bus 5 & Bus 6 & 22.8 \\
Line 8 & Bus 1 & Bus 10 & 1.33 \\
Line 9 & Bus 1 & Bus 9 & 3.22 \\
\hline
\end{tabular}

To assess the impact of integrating the proposed hybrid system that was derived for the optimization analysis in HOMER, an analysis is conducted on the modified network of the existing system. Different scenarios of integrating the proposed solar PV and wind generator were implemented as follows:

Scenario 1 (connecting only solar PV without voltage control): The purpose of this scenario is to assess the impact of integrating only one source, a solar PV. The solar PV system is modeled with a maximum active power output of $3 \mathrm{MW}$ (reactive power is $0 \mathrm{MVAR}$ ) and without voltage control capability. The point of connection of the solar PV to the network will be decided based on the analysis results of the existing system network.

Scenario 2 (connecting both solar PV and wind generator without voltage control): In this scenario, both solar PV and wind generator are modeled with a maximum capacity of $3 \mathrm{MW}$ each. The connection points of each system are determined based on the previous analysis results.

Scenario 3 (connecting wind generator and solar PV with voltage control): The solar PV system in this scenario is modeled to provide voltage control by automatically injecting reactive power to improve the voltage profile at the point of connection and through the entire system.

\section{$5 \quad$ Hybrid System Optimization Results}

The simulation, using HOMER software, of the existing diesel system and the different hybrid systems is presented in this section. The schematic design and the total costs of each system are shown in Fig. 5 and Fig. 6 respectively. Fig. 7 provides the monthly average electricity production of each system as a result of the optimization simulation and the total hourly load served during the full year. 


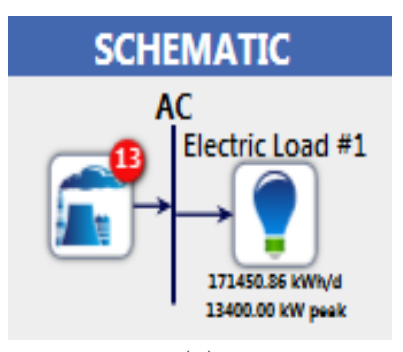

(a)

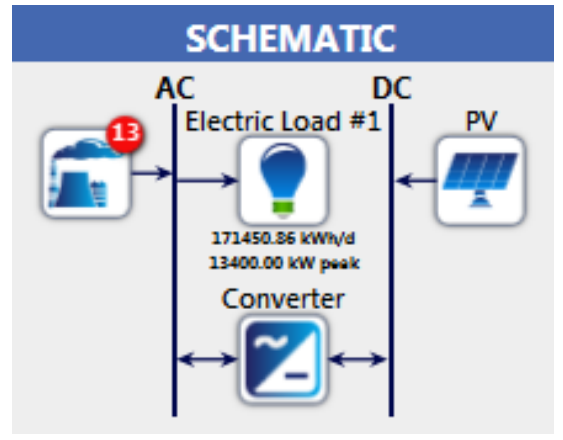

(b)

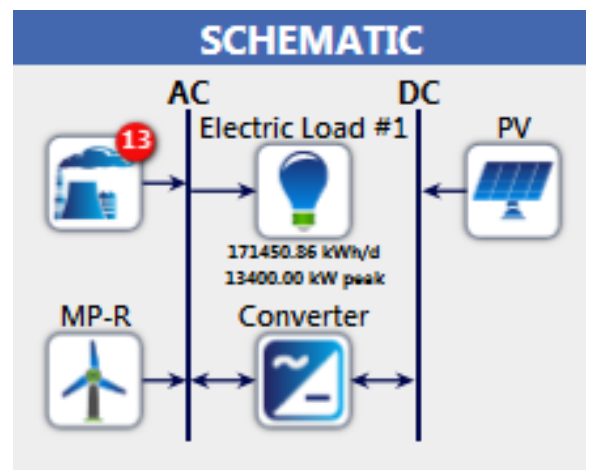

(c)

Figure 5. Schematic design in HOMER software. (a) Diesel generation system, (b) Diesel-solar PV system and (c) Diesel-solar PV-wind generator system.

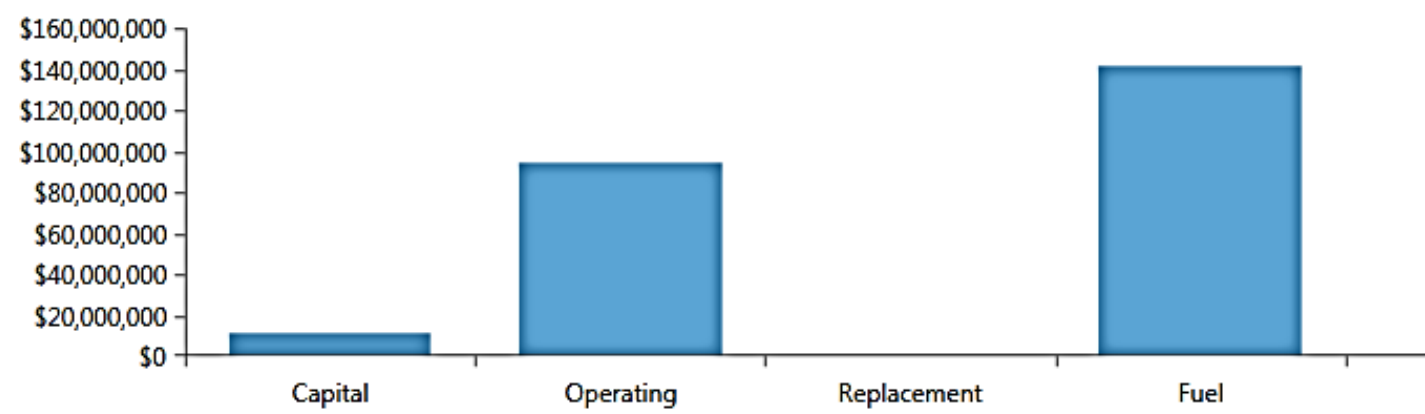

(a)

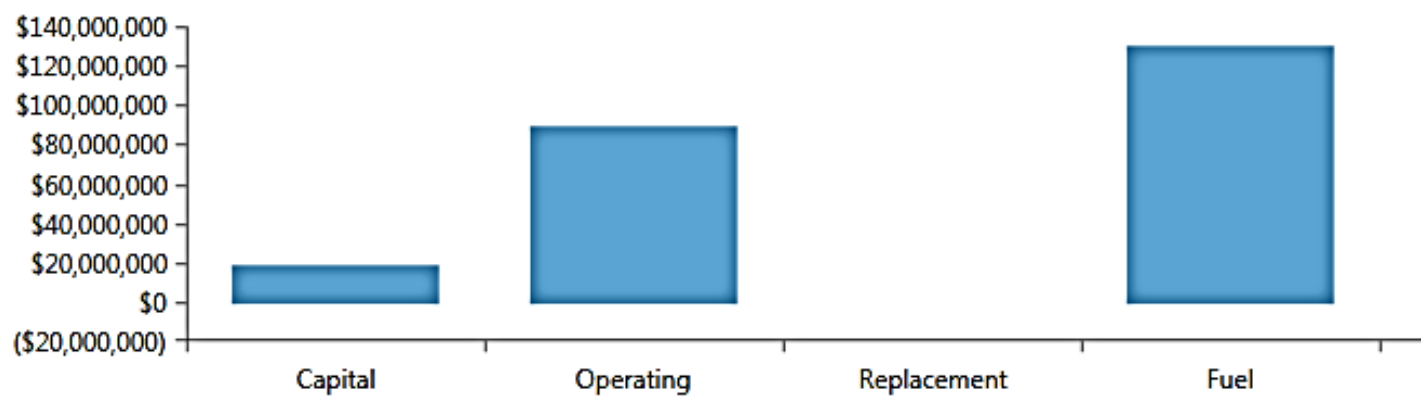

(b)

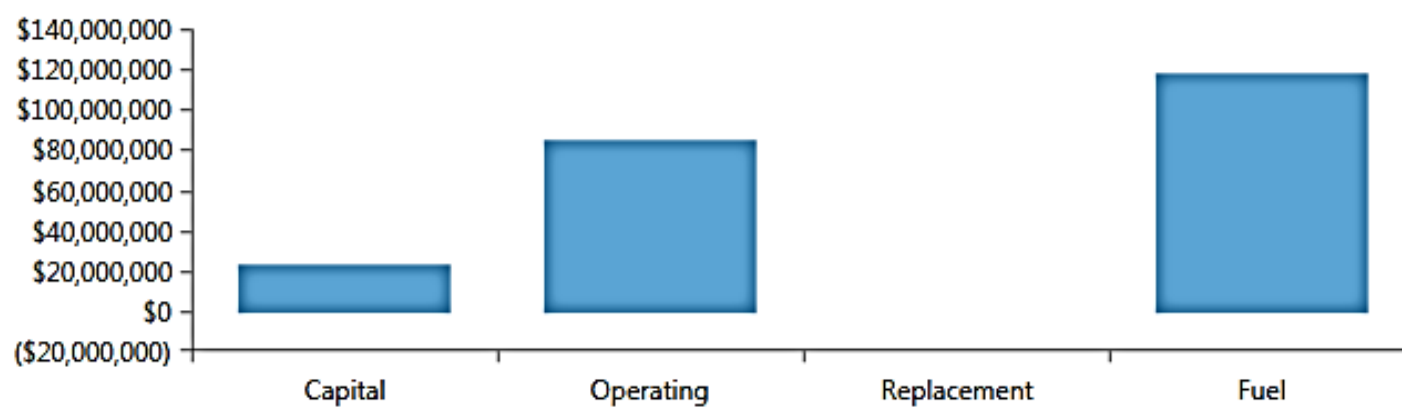

(c)

Figure 6. Total costs for (a) Diesel generation system, (b) Diesel-solar PV hybrid system and (c) Dieselsolar PV-wind generator hybrid system. 


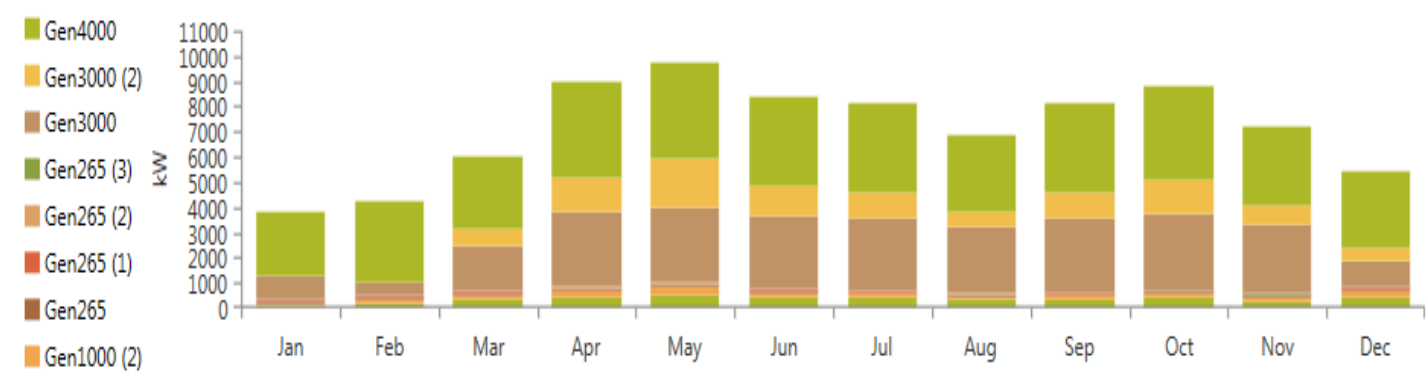

(a)

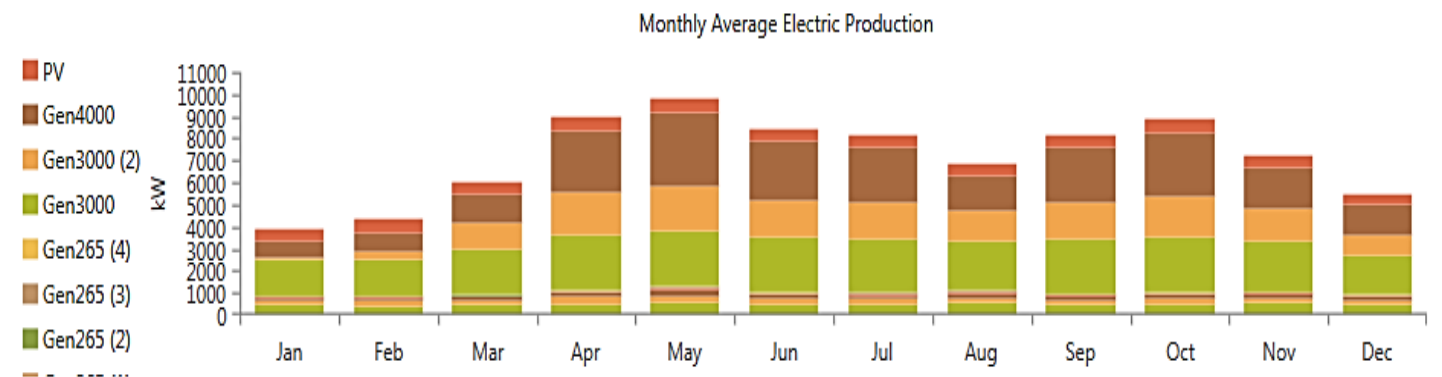

(b)

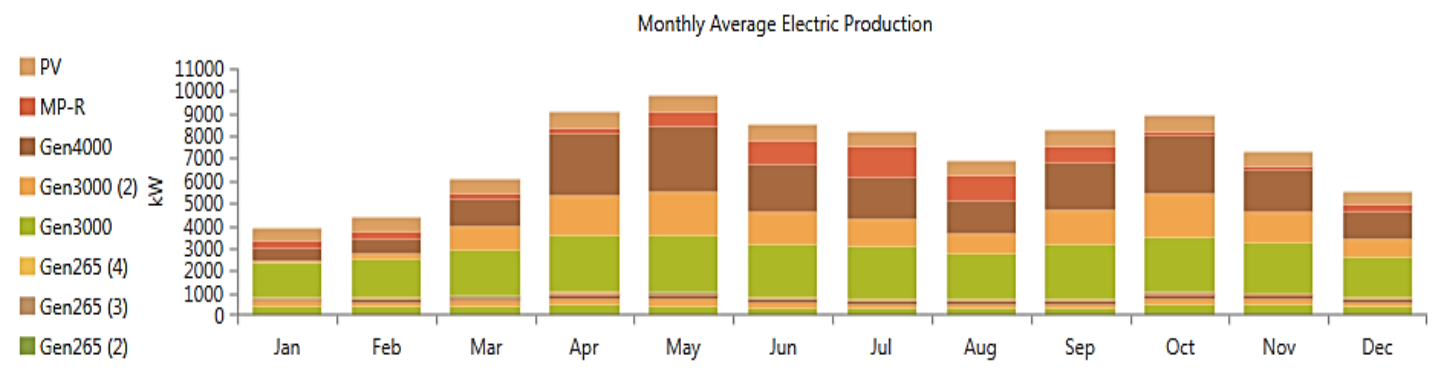

(c)

Figure 7. Monthly average electric production. (a) Diesel generation system, (b) Diesel-solar PV hybrid system and (c) Diesel-solar PV-wind generator hybrid system.

The economic optimization results of the three modeled systems are presented in Table 5. As shown in the table the hybrid systems have higher capital cost than the diesel system. This is due to the high capital cost of the renewable energy technologies compared to the diesel system. By comparing the cost of each system, it is indicated that the diesel-solar PV-wind generator hybrid system reduces the net present cost of the total system by $7 \%$ and $5 \%$ compared with the diesel and the diesel-solar PV systems, respectively. The diesel-solar PV-wind generator hybrid system has the lowest cost of energy among the other two systems (0.272 USDS/kWh). It also reduces the consumption of diesel fuel.

Table 5. Results of optimization analysis and $\mathrm{CO}_{2}$ emission of modelled systems.

\begin{tabular}{|c|c|c|c|c|c|c|c|}
\hline $\begin{array}{l}\text { Modeled } \\
\text { system }\end{array}$ & $\begin{array}{c}\text { Capital } \\
\text { cost } \\
\text { (USD) } \\
\end{array}$ & $\begin{array}{l}\mathrm{NPC} \\
(\mathrm{USD})\end{array}$ & $\begin{array}{c}\mathrm{LCOE} \\
(\mathrm{USD} / \mathrm{kWh})\end{array}$ & $\begin{array}{c}\text { Operating } \\
\text { cost } \\
(\mathrm{USD}) \\
\end{array}$ & $\begin{array}{c}\text { Diesel fuel } \\
\text { consumption } \\
\text { (lt) } \\
\end{array}$ & $\begin{array}{c}\mathrm{CO}_{2} \\
\text { emissions } \\
(\mathrm{kg} / \mathrm{yr}) \\
\end{array}$ & $\begin{array}{c}\% \text { (change } \\
\text { to base- } \\
\text { case model) } \\
\end{array}$ \\
\hline Diesel & $10,800,000$ & $246,961,168$ & 0.291 & $17,421,185$ & $16,317,324$ & $42,968,888$ & - \\
\hline $\begin{array}{c}\text { Diesel-solar } \\
\text { PV }\end{array}$ & $20,200,000$ & $241,601,136$ & 0.285 & $16,331,391$ & $15,088,337$ & $39,732,560$ & $-8 \%$ \\
\hline $\begin{array}{l}\text { Diesel-solar } \\
\text { PV-wind } \\
\text { generator }\end{array}$ & $24,200,000$ & $230,433,728$ & 0.272 & $15,212,542$ & $13,775,870$ & $36,276,412$ & $-16 \%$ \\
\hline
\end{tabular}


The diesel-solar PV-wind generator hybrid system has also the lowest fuel consumption which is $16 \%$ and $9 \%$ less compared to the diesel and diesel-solar PV systems, respectively. The $\mathrm{CO}_{2}$ emissions of each system are shown in Table 5. Based on the above, the diesel-solar PV-wind generator hybrid system was the most suitable system compared to the others, therefore it was the one that was integrated to the existing network and simulations were conducted to assess the impact.

\section{DIgSILENT Simulation Results}

Different scenarios are simulated in DIgSILENT power systems software to assess the impact of connecting the proposed solar PV and wind generator to the distribution network of Masirah Island.

\subsection{Network Analysis without Renewable Energy Sources}

Load flow analysis of the modified network was conducted to obtain real and reactive power, voltage profile and load of the existing network. The network presented in Fig. 4 was used for this simulation. The obtained voltage profile at the 11 and $33 \mathrm{kV}$ side of the network is shown in Table 6 and Fig. 8 .

Table 6. Voltage profile at $11 \& 33 \mathrm{kV}$ busbars - no renewable sources.

\begin{tabular}{cccc}
\hline Bus Name & Nominal Voltage (kV) & $\begin{array}{c}\text { Voltage } \\
(\mathbf{k V})\end{array}$ & $\begin{array}{c}\text { Voltage } \\
(\mathbf{p . u .})\end{array}$ \\
\hline Bus 1 & 11 & 11 & 1 \\
Bus 2 & 11 & 10.98 & 0.99 \\
Bus 3 & 33 & 32.3 & 0.97 \\
Bus 4 & 33 & 32.16 & 0.97 \\
Bus 5 & 11 & 10.51 & 0.95 \\
Bus 6 & 11 & 9.4 & 0.85 \\
Bus 7 & 11 & 10.46 & 0.95 \\
Bus 8 & 11 & 10.45 & 0.95 \\
Bus 9 & 11 & 10.97 & 0.99 \\
Bus 10 & 11 & 10.92 & 0.99 \\
\hline
\end{tabular}

As shown in Fig. 8, busbars 5, 6, 7 and 8 have the lowest voltage magnitude as they are located at the receiving end of the long distribution lines. While the voltage at all busbars are within the voltage range of the voltage limits that the Authority of Electricity Regulation of Oman defines, bus 6 operates below the voltage limit with almost $15 \%$ lower voltage than the nominal voltage.

The loads on the distribution network cables are shown in Table 7 . The loads on 11 and $33 \mathrm{kV}$ cables are below $50 \%$ except for line 7, which supplies bus 6 with a load of $61 \%$.

Table 7. 11 \& $33 \mathrm{kV}$ lines loads.

\begin{tabular}{ccccc}
\hline Line Name & From & To & Length (Km) & Load \% \\
\hline Line 1 & Bus 1 & Bus 2 & 0.46 & 46 \\
Line 2 & Bus 1 & Bus 2 & 0.46 & 46 \\
Line 3 & Bus 3 & Bus 4 & 5 & 20 \\
Line 4 & Bus 3 & Bus 4 & 5 & 20 \\
Line 5 & Bus 5 & Bus 8 & 10.13 & 11 \\
Line 6 & Bus 5 & Bus 7 & 4 & 21 \\
Line 7 & Bus 5 & Bus 6 & 22.8 & 61 \\
Line 8 & Bus 1 & Bus 10 & 1.33 & 46 \\
Line 9 & Bus 1 & Bus 9 & 3.22 & 40 \\
\hline
\end{tabular}


Based on the above, it is clear that the distribution network is weak around busbars 5,7 and 8 , requiring support to stabilize the voltage. Therefore, it is decided that the proposed solar PV and wind generator should be connected to bus 5 and bus 6 of the network.

Three different scenarios of integrating the solar PV and wind generator were considered: a) Solar PV connected to bus 6 without voltage control (PV scenario), b) Solar PV connected to bus 6 and wind generator to bus 5 without voltage control (wind and PV scenario) and c) Wind generator connected to bus 5 and solar PV to bus 6 with voltage control capability (wind and PV with voltage control scenario). The results of load flow analysis of the different scenarios are presented in the following sections.

\subsection{Network Analysis with Solar PV}

Based on the results of section 6.1 , bus 6 operates outside the voltage range therefore a decision has been made to connect the solar PV to bus 6. The solar PV is modeled with a maximum installed capacity of $3 \mathrm{MW}$ and without voltage control capability. Table 8 and Fig. 8 present the voltage profile at 11 and $33 \mathrm{kV}$ busbars following the connection of the $3 \mathrm{MW}$ solar PV to bus 6 . The voltage level at busbars 5, 6, 7 and 8 is improved. However, the voltage profile of bus 6 remains below the acceptable limit (0.92 p.u.). The load on line 7 decreased significantly as the solar PV supplies $3 \mathrm{MW}$ out of the 3.4 MW of the load connected to the line.

\subsection{Network Analysis with Solar PV and Wind Generator}

In this scenario the proposed solar PV and wind generator are both connected to the network. As the solar PV remains connected to bus 6, the wind generator is connected to bus 5 with an objective to improve the voltage profile further at this weak part of the system. Both solar PV and wind generator are modeled with a maximum capacity of $3 \mathrm{MW}$ each. The voltage profile on each busbar is presented in Table 8 and Fig. 8. In comparison to the results of the previous scenario, the integration of wind generator at bus 5 has improved the voltage profile at the point of connection but remained constant at busbars 6,7 , and 8 with bus 6 to still operate below the minimum limit.

Table 8. Voltage profile at $11 \& 33 \mathrm{kV}$ busbars for three different scenarios of solar PV and wind generator integration.

\begin{tabular}{|c|c|c|c|c|c|c|c|}
\hline \multirow[t]{2}{*}{$\begin{array}{c}\text { Bus } \\
\text { Name }\end{array}$} & \multirow[t]{2}{*}{$\begin{array}{l}\text { Nominal } \\
\text { Voltage } \\
(\mathrm{kV})\end{array}$} & \multicolumn{2}{|c|}{$\begin{array}{c}3 \mathrm{MW} \text { solar PV } \\
\text { connected at bus } 6\end{array}$} & \multicolumn{2}{|c|}{$\begin{array}{l}3 \mathrm{MW} \text { solar PV at bus } 6 \\
\text { and } 3 \mathrm{MW} \text { wind at bus } 5 \\
\text { without voltage control }\end{array}$} & \multicolumn{2}{|c|}{$\begin{array}{c}3 \mathrm{MW} \text { solar PV at bus } 6 \\
\text { and } 3 \mathrm{MW} \text { wind at bus } 5 \\
\text { with voltage control }\end{array}$} \\
\hline & & $\begin{array}{c}\text { Voltage } \\
(\mathrm{kV})\end{array}$ & $\begin{array}{l}\text { Voltage } \\
\text { (p.u.) }\end{array}$ & $\begin{array}{c}\text { Voltage } \\
(\mathrm{kV})\end{array}$ & $\begin{array}{l}\text { Voltage } \\
\text { (p.u.) }\end{array}$ & $\begin{array}{c}\text { Voltage } \\
(\mathrm{kV})\end{array}$ & $\begin{array}{c}\text { Voltage } \\
\text { (p.u.) }\end{array}$ \\
\hline Bus 1 & 11 & 11 & 1 & 11 & 1 & 11 & 1 \\
\hline Bus 2 & 11 & 10.98 & 0.99 & 10.99 & 0.99 & 10.99 & 1 \\
\hline Bus 3 & 33 & 32.42 & 0.98 & 32.44 & 0.98 & 32.81 & 0.99 \\
\hline Bus 4 & 33 & 32.34 & 0.97 & 32.41 & 0.98 & 32.81 & 0.99 \\
\hline Bus 5 & 11 & 10.6 & 0.96 & 10.62 & 0.97 & 10.89 & 0.99 \\
\hline Bus 6 & 11 & 10.09 & 0.92 & 10.12 & 0.92 & 10.82 & 0.98 \\
\hline Bus 7 & 11 & 10.55 & 0.96 & 10.57 & 0.96 & 10.97 & 0.98 \\
\hline Bus 8 & 11 & 10.54 & 0.96 & 10.56 & 0.96 & 10.98 & 0.99 \\
\hline Bus 9 & 11 & 10.97 & 0.99 & 10.97 & 0.99 & 10.97 & 1 \\
\hline Bus 10 & 11 & 10.92 & 0.99 & 10.99 & 0.99 & 10.92 & 0.99 \\
\hline
\end{tabular}

\subsection{Network Analysis with Wind Generator and Solar PV Voltage Control}

The solar PV and wind generator are modeled with the maximum capacity of $3 \mathrm{MW}$ each. The solar PV is modeled with voltage control capability to inject reactive power to the system with an objective to improve the voltage profile on bus 6 . The voltage profiles at 11 and $33 \mathrm{kV}$ busbars are presented in Table 8 and Fig. 8. Allowing the solar PV to automatically inject reactive power to the system, the 
voltage level is improved and all busbars operate within the acceptable voltage limit as shown in Fig. 8. Fig. 8 presents a comparison of voltage profile on all busbars in all modelled scenarios. Based on this comparison, it is evident that the integration of the proposed hybrid renewable energy system to the existing network on the island results many benefits such as voltage profile improvements and line load reduction.

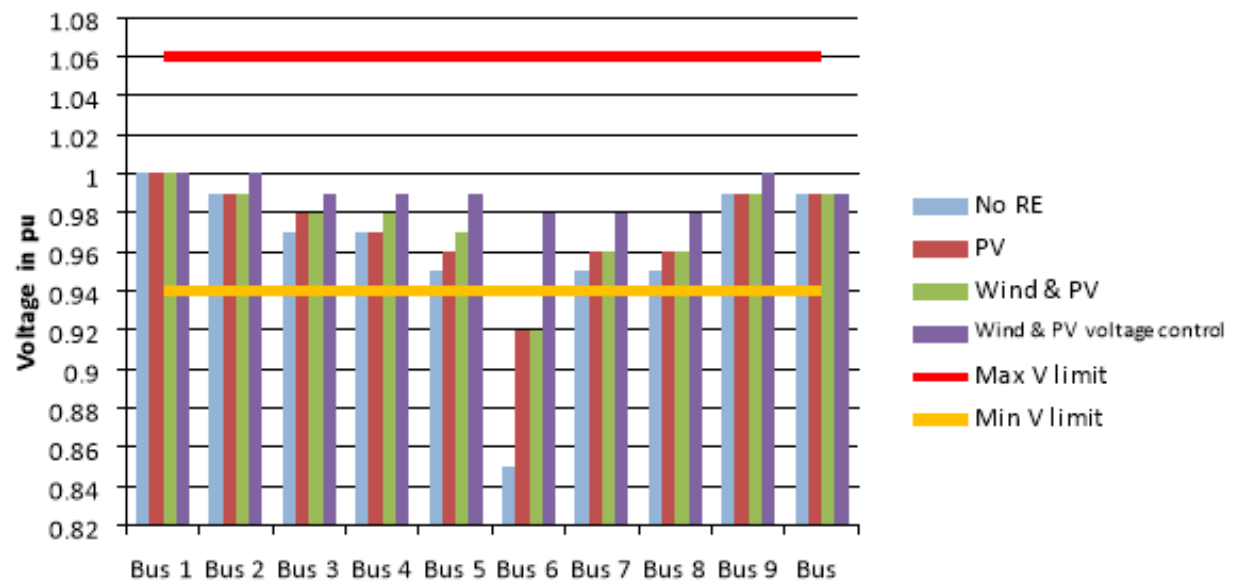

Figure 8. Comparison of voltage profile at $11 \& 33 \mathrm{kV}$ busbars for different scenarios.

\section{Conclusion}

Off-grid power systems mostly depend on a single source of generation. This approach has raised concerns and challenges on security and reliability of supply, especially in off-grid islands. In this work, the technical and economic feasibility of renewable energy integration with an existing diesel power system was studied. The island off-grid power system in Masirah, Oman was considered as the site of the study. An analysis of the load demand profile of the existing system and an assessment of the renewable energy resources on the island were conducted. HOMER optimization tool was used to find out the optimal size of the hybrid energy system. The optimization results indicated that the diesel, solar PV and wind generator hybrid system presented the most economic viable hybrid system. Although this hybrid system has the highest capital cost among other considered scenarios, it has the lowest net present cost, energy cost and operating cost. Then the selected hybrid energy system was modelled and simulated using the DIgSILENT Power Factory to assess the impact of renewable energy technologies integration into the existing network. The obtained results have indicated that the connection of the proposed hybrid system to the existing network of Masirah Island improves significantly the voltage profiles.

\section{References}

1. J. Barzola, M. Espinoza and F. Cabrera, "Analysis of hybrid solar/wind/diesel renewable energy system for offgrid rural electrification," Int. Journal of Renewable Energy Research, vol. 6, no. 3, 2016, pp. 1146-1152.

2. N. Bizon, H. Shayeghi and N. Mahdavi Tabatabaei, "Analysis, control and optimal operations in hybrid power systems: Advanced techniques and applications for linear and nonlinear systems," in SpringerLink eBook Collection, London, 2013.

3. A. S. Al Busaidi, H. A. Kazem, A. H. Al-Badi and M. F. Khan, "A review of optimum sizing of hybrid PV-Wind renewable energy systems in Oman," Renewable and Sustainable Energy Reviews, vol. 53, 2016, pp. 185-193.

4. Y.S. Mohammed, M. W. Mustafa and N. Bashir, "Hybrid renewable energy systems for offgrid electric power: review of substantial issues," Renewable \& Sustainable Energy Reviews, vol. 35, 2014, pp. 527-539.

5. R. Luna-Rubio, M. Trejo-Perea, D. Vargas-Vázquez and G. J. Ríos-Moreno, "Optimal sizing of renewable hybrids energy systems: A review of methodologies," Solar Energy, vol. 86, no. 4, 2012, pp. 1077-1088. 
6. S. Sinha and S. S. Chandel, "Review of software tools for hybrid renewable energy system," Renewable 8 Sustainable Energy Reviews, vol. 32, 2014, pp. 192-205.

7. P. Zhou, R. Y. Jin and L. W. Fan, "Reliability and economic evaluation of power system with renewables: A review," Renewable and Sustainable Energy Reviews, vol. 58, 2016, pp. 537-547.

8. S. B. Darling, F. You, T. Veselka and A. Velosa, "Assumptions and the levelised cost of energy for photovoltaics," Energy 83 Environmental Science, vol. 4, no. 9, 2011, pp. 3133-3139.

9. Rural Areas Electricity Company, 2015. Capability Statements-Reefiah, Available: http://reefiah.com/reports/capability-statement

10. V. Vita, T. Alimardan, L. Ekonomou, "The impact of distributed generation in the distribution networks' voltage profile and energy losses," Proceedings. 9th IEEE European Modelling Symposium on Mathematical Modelling and Computer Simulation, Madrid, Spain, 2015, pp. 260-265.

11. HOMER Renewable Energy Microgrid Software - Distributed Power and Microgrid Design Support, Available: http://www.homerenergy.com/software.html

12. PowerFactory-DIgSILENT Germany, Available: http://www.digsilent.de/index.php/products-powerfactory.html

13. V. Lupic "Simulation software in manufacturing environments: a users' survey," Journal of Computing and Information Technology, vol. 1, no. 3, 2010, pp. 205-212.

14. M. Bovone, V. De Ferrari and R. Manuelli, "How to choose a useful simulation software," in Proceedings of European Simulation Multiconference, Rome, Italy, 2011, pp.250-270.

15. International Renewable Energy Agency: Sultanate of Oman Renewables Readiness Assessment, Available: http://www.irena.org/DocumentDownloads/Publications/IRENA_RRA_Oman_2014_LR.pdf

16. NASA Surface meteorology and Solar Energy, Available:

https://eosweb.larc.nasa.gov/cgi-bin/sse/grid.cgi?email=skip@larc.nasa.gov, accessed 16 October 2016

17. X. Liu, P. Wang and P. C. Loh, "A hybrid AC/DC microgrid and its coordination control," IEEE Transactions on Smart Grid, vol. 2, no. 2, 2011, pp. 278-286. 